\title{
THE LARGEST PARACENTRIC INVERSION, THE HIGHEST RATE OF RECOMBINANT SPERMATOZOA. CASE REPORT: 46,XY, inv(2)(q21.2q37.3) AND LITERATURE REVIEW
}

\author{
Yapan $\mathrm{CC}^{1, *}$, Beyazyurek $\mathrm{C}^{1}$, Ekmekci $\mathrm{CG}^{1}$, Kahraman $\mathrm{S}^{2}$
}

\begin{abstract}
*Corresponding Author: Cigdem Cinar Yapan, MSc., Reproductive Genetics Laboratory, Istanbul Memorial Hospital, Piyalepasa Street, 34385 Sisli, Istanbul, Turkey. Tel.: +90-212-314-6666. Fax: +90-212-314-6657.

E-mail: cigdemcinar78@gmail.com
\end{abstract}

\begin{abstract}
Carriers of inversions involving euchromatic regions are at risk of having unbalanced offspring due to meiotic crossover. In carriers, recombination can occur during gametogenesis and cause genetically unbalanced sperm and subsequently unbalanced embryos. Here we present segregation analysis results of an infertile male with $46, \mathrm{XY}, \operatorname{inv}(2)$ (q21.2q37.3) using fluorescent in situ hybridization (FISH) on sperm cells. This is the largest paracentric inversion (PAI) reported so far in a meiotic segregation analysis study. Sperm FISH revealed $28.0 \%$ recombinant spermatozoa rate for chromosome 2, which was the highest rate in PAI carriers in the literature. Our results indicate a clear correlation between the size of the inverted segment and the frequency of the recombinant spermatozoa. The results of the FISH analysis with the information of unbalanced spermatozoa rate can provide accurate counseling on the genetic risk of infertility.
\end{abstract}

Keywords: Chromosome 2; Male infertility; Paracentric inversion(s) (PAIs); Recombinant spermatozoa; Sperm; Fluorescent in situ hybridization (FISH)

\footnotetext{
${ }^{1}$ Reproductive Genetics Laboratory, Istanbul Memorial Hospital, Istanbul, Turkey

${ }^{2}$ In Vitro Fertilization Center, Istanbul Memorial Hospital, Istanbul, Turkey
}

\section{INTRODUCTION}

Balanced paracentric inversions (PAIs) are structural chromosomal rearrangements that are formed on a chromosome arm involving two breaks and rejoining of the chromosome segment after $180^{\circ}$ rotation. In humans, the incidence of PAI ranges from 0.1$0.5 \%[1,2]$.

During meiosis, if a crossover occurs within the inversion loop, four segregational products are formed [3,4] (Figure 1). Gametes containing unbalanced chromosomes very rarely give rise to a viable zygote. However, several cases of viable recombinant offspring have been reported [5-7]. Furthermore, the relationship between infertility and PAIs reveals an association with recurrent miscarriage and infertility problems among PAI carriers [8,9], indicating the real recombination frequency in PAI must be higher than suspected from liveborn data [10]. Chromosomal analysis of gametes helps to clear up this controversial issue and provide detailed information about the percentage of viable recombinants.

Ten male carriers of PAI have been investigated to date and the frequency of recombinant spermatozoa varied from 0.0 to $12.6 \%$ [10-16]. The present case is the second with the meiotic segregation analysis performed for chromosome 2 in a male PAI carrier. In this report, we aimed to evaluate the rate of recombinant spermatozoa in a PAI carrier [46,XY,inv(2)(q21.2q37.3)] using a fluorescent in 
situ hybridization (FISH) technique. Furthermore, the impact of this PAI was also assessed on aneuploidies of other chromosomes to identify any possibility of interchromosomal effect (ICE) and consequences on fertility.

\section{MATERIALS AND METHODS}

Patients. A 43-year-old man and his 42-year-old wife were referred to the Istanbul Memorial Hospital In Vitro Fertilization (IVF) and Reproductive Genetics Center, Istanbul, Turkey, with primary infertility and a history of repeated implantation failures in their nine IVF attempts. Cytogenetic analysis reports indicated $46, X Y, \operatorname{inv}(2)$ (q21.2q37.3) (Figure 2) and 46,XX, for the man and woman, respectively. A sperm-FISH evaluation was proposed to determine the meiotic segregation profiles of the PAI.

Sperm Fluorescent In Situ Hybridization Analysis. Sperm samples were collected in a sterile container after 3 days of sexual abstinence. All procedures including fixation, pretreatment, probe

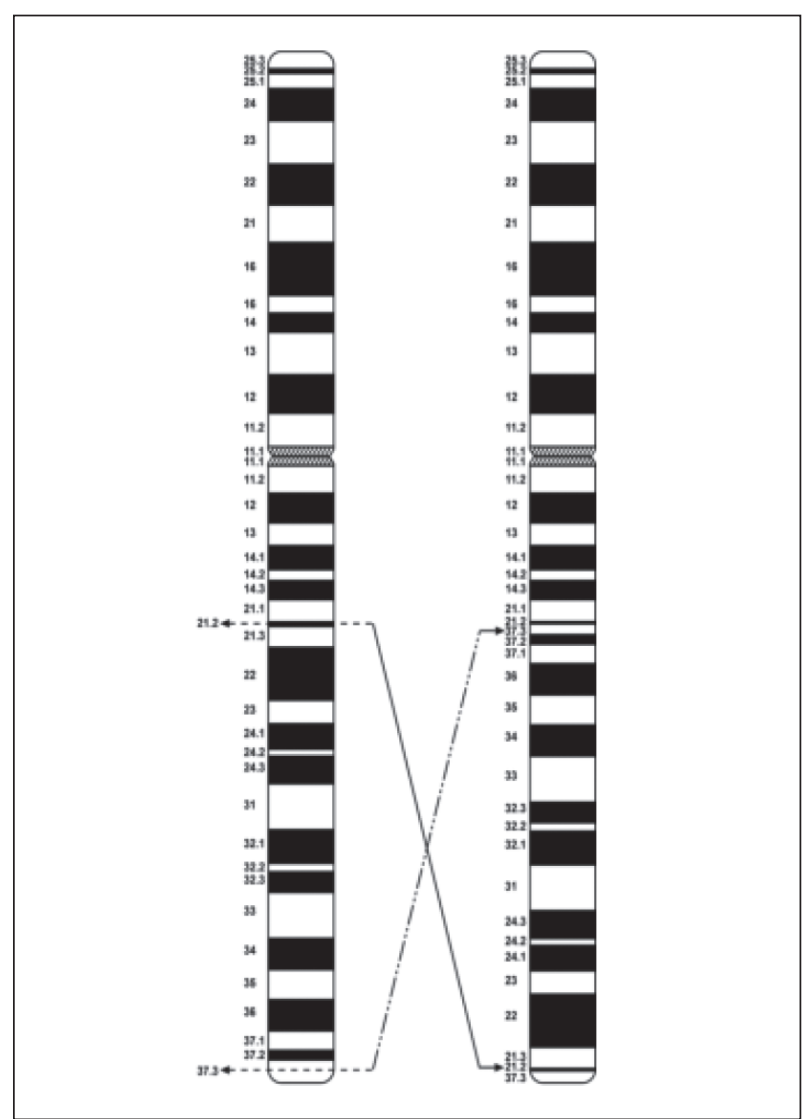

Figure 2. Paracentric inversion showing the breakpoints on chromosome 2. application, hybridization, and washing steps were carried out as described previously [17]. Hybridization was performed with two specific telomeric and centromeric probe mixtures. The first mixture included Telomeric (Tel) $2 p$ (Spectrum Green), Tel 2q (Spectrum Orange) and Centromeric (Cen) 18 (Spectrum Aqua) as a control probe. The second mixture included Tel $2 \mathrm{p}$ (Spectrum Green), Cen 2 (Spectrum Orange) and Cen 18 (Spectrum Aqua) (Abbott Molecular, Abbott Park, North Chicago, IL, USA). In order to evaluate aneuploidies of other chromosomes or any possible ICE, probes specific for chromosomes 13, 15, 17, 18, 21, $\mathrm{X}$ and $\mathrm{Y}$ were also included in the study. The 13, 18, 21, X and Y probes were in our routine aneuploidy panel. Probes specific for chromosomes 15 and 17 were selected randomly in order to increase the number of chromosomes. Analysis criteria that have been described elsewhere [18] was followed.

In Vitro Fertilization Study. The couple underwent IVF treatment at the IVF and Reproductive Genetics Center at the Memorial Hospital, Istanbul,

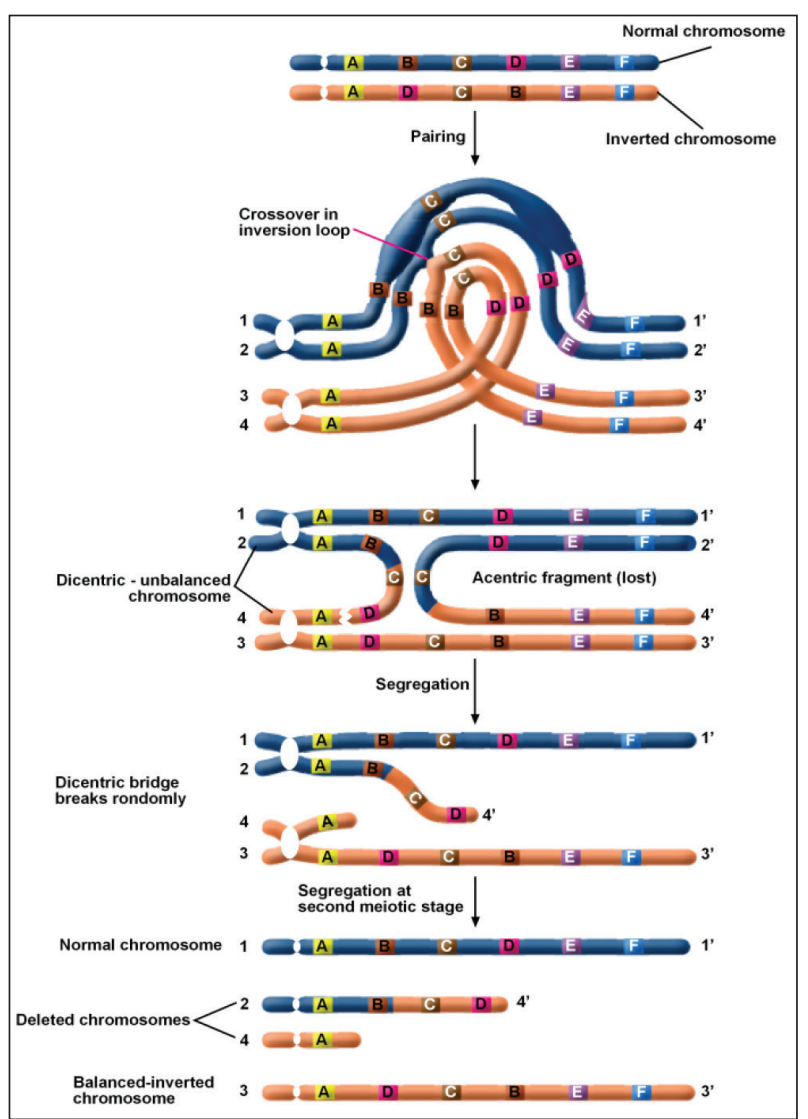

Figure 1. Meiotic segregation products of paracentric inversion. 


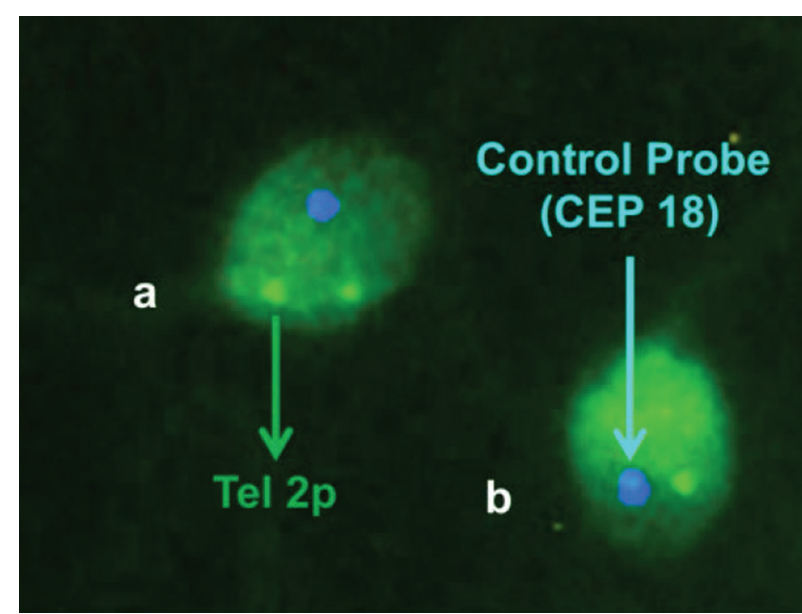

Figure 3. Images of spermatozoa with dicentric and deleted products for chromosome 2 with two green/no orange signal (a) and one green/no orange signal (b) for telomeric $2 \mathrm{p}$ and $2 \mathrm{q}$, respectively.

Turkey. In vitro fertilization, embryological culture conditions have been described previously [19]. Written informed consent was obtained from the couple before they underwent IVF.

\section{RESULTS}

Meiotic segregation analysis of the PAI for chromosome 2 revealed that 378 spermatozoa were abnormal $(28.0 \%)$ (Figure 3$)$. The rate of normal or balanced (inverted) spermatozoa was $72.0 \%$ (Figure 4). The aneuploidy rates for chromosomes 13, $15,17,18,21$, and XY were 1.2, 0.92, 8.4, 1.2, 0.9 and $1.5 \%$, respectively (Table 1 ).

As a result of hyperstimulation, five oocytes were picked up, four of them were matured and fertilized after intracytoplasmic sperm injection (ICSI)

Table 1. Sperm-FISH results for chromosomes $2,13,15,17,18,21$, and XY.

\begin{tabular}{|c|c|}
\hline Chromosome & Abnormal (\%) \\
\hline 2 & 28.00 \\
\hline 13 & 1.20 \\
\hline 15 & 0.92 \\
\hline 17 & 8.40 \\
\hline 18 & 1.20 \\
\hline 21 & 0.90 \\
\hline XY & 1.50 \\
\hline Diploidy & 1.25 \\
\hline
\end{tabular}

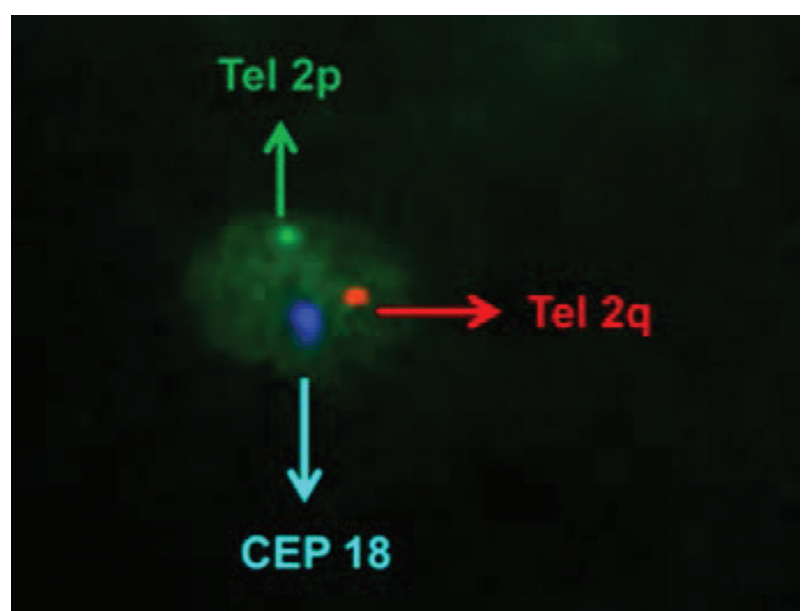

Figure 4. Images of a normal or inverted spermatozoa for chromosome 2 with one signal for telomeric $2 p, 2 q$ and the control probe.

[20]. Four zygotes were cultured until day 3 . Two of these embryos were arrested and the other two were slow-growing embryos. Unfortunately, embryo biopsy and preimplantation genetic diagnosis (PGD) could not be performed due to poor quality of the embryos. Two grade III embryos were transferred on the third day of embryonic growth without genetic analysis. Pregnancy was not achieved in this cycle.

\section{DISCUSSION}

Although PAIs are generally considered to be harmless without phenotypic consequences in carriers [10], recombination can occur during gametogenesis, can cause genetically unbalanced gametes, and subsequently, unbalanced embryos. This could cause repeated IVF failures or repeated pregnancy loss, which is more frequently seen among inversion carriers compared to the normal population. Despite apparently being "balanced," an inversion might disrupt a critical gene and cause an associated phenotype $[21,22]$. Furthermore, small cryptic deletions or duplications around breakpoints may have an effect on the phenotype.

In our case, the length of the inverted segment was the largest one reported in other PAI cases published to date. The inverted segment contained almost $43.0 \%$ of the whole chromosome and was approximately $103 \mathrm{Mbp}$ in length. Subsequently, sperm-FISH analysis revealed $28.0 \%$ of recom- 
Table 2. Results of segregation analyses of paracentric inversions.

\begin{tabular}{|l|c|c|c|c|c|c|c|c|l|c|}
\hline & \multicolumn{2}{|c|}{$\begin{array}{c}\text { Inverted } \\
\text { Segment Size }\end{array}$} & $\begin{array}{c}\text { Number of } \\
\text { Spermatozoa }\end{array}$ & $\begin{array}{c}\text { Non } \\
\text { Recombinants } \\
\text { (\%) }\end{array}$ & $\begin{array}{c}\text { Recom- } \\
\text { binants }\end{array}$ & $\begin{array}{c}\text { Duplicated/ } \\
\text { Deficient } \\
\text { Chromosomes }\end{array}$ & $\begin{array}{c}\text { Bicentric } \\
\text { Chromo- } \\
\text { somes }\end{array}$ & Method & References \\
\hline Inversion & $\mathrm{Mb}$ & $\%^{\mathrm{a}}$ & & Normal & Inverted & $\%$ & $\%$ & $\%$ & & \\
\hline inv(2)(q21.2q37.3) & 103 & 42.5 & 1350 & 72.0 & - & 28.00 & 24.0 & 4.0 & sperm FISH & this study \\
\hline inv(9)(q21.2q34.13) & 54 & 39.0 & 1608 & 44.7 & 42.7 & 12.60 & 11.3 & 1.3 & breakpoint FISH & 10 \\
\hline inv(5)(q13.3q33.1) & 75 & 41.0 & 4807 & 45.6 & 44.7 & 9.70 & 8.7 & 1.0 & breakpoint FISH & 10 \\
\hline inv(14)(q23.3q32.13) & 30 & 29.0 & 7670 & 49.6 & 46.7 & 3.70 & 3.4 & 0.3 & breakpoint FISH & 10 \\
\hline inv(2)(q14.2q24.3) & 49 & 20.0 & 496 & $?$ & - & 0.80 & $?$ & 0.8 & sperm FISH & 14 \\
\hline inv(12)(q15q24.1) & 44 & 33.0 & 1000 & $?$ & - & 0.50 & $?$ & 0.5 & sperm FISH & 16 \\
\hline inv(11)(q13.2q14.3) & 27 & 20.0 & 1001 & $?$ & - & 0.40 & $?$ & 0.4 & sperm FISH & 16 \\
\hline inv(4)(p14p15.3) & 11 & 5.0 & 8158 & $?$ & - & 0.03 & $?$ & $?$ & sperm FISH & 15 \\
\hline inv(7)(q11q22) & 50 & 32.0 & 94 & 36.0 & 63.0 & 0.00 & 0.0 & 0.3 & sperm karyotype & 11 \\
\hline inv(9)(q32q34.4) & 32 & 24.0 & 282 & $?$ & - & 0.00 & 0.0 & 0.0 & sperm typing & 12 \\
\hline inv(14)(q24.1q32.1) & 27 & 26.0 & 120 & 42.0 & 58.0 & 0.00 & 0.0 & 0.0 & sperm karyotype & 13 \\
\hline
\end{tabular}

${ }^{a}$ The percentage of inverted segment size was calculated for the whole chromosome.

binant spermatozoa, which was the highest rate among PAI carriers published in the literature. Our results are in line with the previous observations, supporting a clear correlation between the size of the inverted segment and the frequency of the recombinant spermatozoa (Table 2).

Some previous studies have mentioned that a significant level of unbalanced gametes would require a minimum inversion size of $100 \mathrm{Mbp}$ and minimum segment proportion of $50.0 \%$ of the chromosome $[23,24]$ for pericentric inversions (PEIs). Morel et al. [24], suggested that significant number of recombinants are produced when the inverted segment size is $>50.0 \%$ of the total length of the inverted chromosome. For PAIs, however, there is not enough data regarding the factors affecting segregation. Our findings show that a significant rate of unbalanced gametes can be detected even if the inverted segment size was less than $50.0 \%$ of the whole chromosome $(42.5 \%)$.

Recently, Bhatt et al. [25], mentioned that the formation of recombinants depends on the presence and number of hot spots (HSs) and the recombination frequency in the particular region. These are called HSs, high recombination rate spot (HRS) and very high recombination rate spot (VHRS). The higher the number of recombination HSs around the breakpoints, within the inverted segment, the higher the probability of formation of double crossovers and recombination [25]. Breakpoints were in critical regions for our case. One of them was in or around a HS (2q21.2) and the other was probably in a VHRS (2q37.3). All this knowledge contributes to explain our high recombination rate.

Interchromosomal effect has been investigated in a few previous studies with a maximum of five chromosomes including 13, 18, 21, $\mathrm{X}$ and $\mathrm{Y}$ and was demonstrated in some studies (e.g., [15]) whilst not in others $[12,16]$. To the best of our knowledge, this is only the second study (after Anton et al. [15]), in which significantly high ICE has been found in a PAI carrier. In this study, an especially high aneuploidy rate for chromosome 17 was found. Inversion loops have been shown to be associated with other chromosome pairs [26]. The high rate of aneuploidy for chromosome 17 found in this study could be attributed to an ICE due to an association of inversion loop with chromosome 17 by a mechanism similar to which Batanian and Hulten [26] proposed.

In male carriers, sperm FISH studies allow counselors to offer patients better reproductive genetic advice prior to a PGD cycle. Information of unbalanced spermatozoa rate can provide tips for counseling on the genetic risk of infertility. A 5.0\% technical error rate for FISH applications must be taken into consideration when counseling patients. Although imbal- 
ances due to recombination could easily be detected with the FISH technique, small deletions that might occur at or near the inversion breakpoints could not be detected, unless direct sequencing of the breakpoint regions have been performed.

For the couples with an increased rate of unbalanced gametes, the PGD technique offers a healthy pregnancy, eliminating unbalanced or aneuploid embryos from transfer. With the use of more recent techniques such as array-comparative genomic hybridization (a-CGH), it is possible to select the normal or balanced embryos and also exclude ICE by analyzing all 24 chromosomes in one day [27]. However, the embryos of our patient were not suitable for biopsy since they had a poor embryonic development. It is well known that most early losses are associated with chromosomal abnormalities in sperm or egg, and result in arrested embryonic development and/or failed implantation [28]. Such a poor development might be the consequence of the high rates of recombinant gametes, variety of unpredictable unbalanced chromosome products and small microscopic deletions that could have resulted from the PAI. In addition, in our case, multiple crossover events could be likely for this large and susceptible segment to recombination.

Our results support that not every PAI is innocent as they could be the reason of high abnormality rates in sperm that might have been associated with repeated IVF failures and pregnancy losses. To date, the possibility of associations of PAI on chromosome 2 with fertility and sexual developmental problems have been discussed in several reports [14,29-31]. However, how far the impact of PAIs on poor obstetrics history should be further evaluated in order to be demonstrated as the primary cause of the infertility in this couple.

This study demonstrated the importance of sperm FISH evaluation in the genetic counseling and assisted reproductive technology (ART) practices. It also gives further evidence of a possible ICE and a possible impact of additive consequences on fertility in PAI carriers.

\section{ACKNOWLEDGMENTS}

The authors are very grateful to Ayhan Eminoğlu from the Information Technology Department at the Memorial Hospital, Istanbul, Turkey, for his valu- able contribution to the figures. We also would like to thank Dr. Mustecep Kavrut from the IVF Center at the Memorial Hospital, Istanbul, Turkey, for his valuable assistance in the evaluation of the clinical information.

Declaration of Interest. The authors report no conflicts of interest. The authors alone are responsible for the content and writing of this article.

\section{REFERENCES}

1. Fryns JP, van den Berghe H. Paracentric inversion in man: personal experience and review of the literature. Hum Genet. 1980; 54(3): 413-416.

2. Hook EB, Schreinemachers DM, Willey AM, Cross PK. Inherited structural cytogenetic abnormalities detected incidentally in fetuses diagnosed prenatally: frequency, parental-age associations, sex-ratio trends and comparisons with rates of mutants. Am J Hum Genet. 1984; 36(2): 422-443.

3. Therman E. Human Chromosomes, Structure, Behavior, Effects. New York, NY: SpringerVerlag, 1980.

4. Munné S. Preimplantation genetic diagnosis of structural abnormalities. Mol Cell Endocrinol. 2001; 183 (Suppl 1): S55-S58.

5. Worsham MJ, Miller DA, Devries JM, Mitchell AR, Babu VR, Surli V, et al. A dicentric recombinant 9 derived from a paracentric inversion: Phenotype, cytogenetics, and molecular analysis of centromeres. Am J Hum Genet. 1989; 44(1): 115-123.

6. Phelan MC, Stevenson RE, Anderson EV Jr. Recombinant chromosome 9 possibly derived from breakage and reunion of sister chromatids within a paracentric inversion loop. Am J Med Genet. 1993; 46(3): 304-308.

7. Lefort $\mathrm{G}$, Blanchet $\mathrm{P}$, Belgrade N, Rivier F, Chaze AM, Sarda P, et al. Stable dicentric duplication-deficiency chromosome 14 resulting from crossing-over within a maternal paracentric inversion. Am J Med Genet A. 2003; 118A(2): 333-338.

8. Madan K. Paracentric inversions: A review. Hum Genet. 1995; 96(5): 503-515.

9. Madan K, Nieuwint AW. Reproductive risks for paracentric inversion heterozygotes: Inver- 
sion or insertion? That is the question. Am J Med Genet. 2002; 107(4): 340-343.

10. Bhatt S, Moradkhani K, Mrasek K, Puechberty J, Manvelyan M, Hunstig F, et al. Breakpoint mapping and complete analysis of meiotic segregation patterns in three men heterozygous for paracentric inversions. Eur J Hum Genet. 2009; 17(1): 44-50.

11. Martin RH. Sperm chromosome analysis in a man heterozygous for a paracentric inversion of chromosome 7 (q11q22). Hum Genet. 1986; 73(2): 97-100.

12. Brown GM, Leversha M, Hulten M, FergusonSmith MA, Affara NA, Furlong RA. Genetic analysis of meiotic recombination in humans by use of sperm typing: Reduced recombination within a heterozygous paracentric inversion of chromosome 9q32-q34.3. Am J Hum Genet. 1998; 62(6): 1484-1492.

13. Martin RH. Sperm chromosome analysis in a man heterozygous for a paracentric inversion of chromosome 14 (q24.1q32.1). Am J Hum Genet. 1999; 64(5): 1480-1484.

14. Devine DH, Whitman-Elia G, Best RG, Edwards JG. Paternal paracentric inversion of chromosome 2: A possible association with recurrent pregnancy loss and infertility. J Assist Reprod Genet. 2000; 17(5): 293-296.

15. Anton E, Vidal F, Egozcue J, Blanco J. Genetic reproductive risk in inversion carriers. Fertil Steril. 2006; 85(3): 661-666.

16. Vialard F, Delanete A, Clement P, Simon-Bouy B, Aubriot FX, Selva J. Sperm chromosome analysis in two cases of paracentric inversion. Fertil Steril. 2007; 87(2): 418.e1-418.e5.

17. Kahraman S, Findikli N, Biricik A, Oncu N, Ogur C, Sertyel S, et al. Preliminary FISH studies on spermatozoa and embryos in patients with variable degrees of teratozoospermia and a history of poor prognosis. Reprod Biomed Online. 2006; 12(6): 752-761.

18. Martin RH, Rademaker A. Reliability of aneuploidy estimates in human sperm: Results of fluorescence in situ hybridization studies using two different scoring criteria. Mol Reprod. 1995; 42(1): 89-93.

19. Findikli N, Kahraman S, Kumtepe Y, Donmez E, Biricik A, Sertyel S, et al. Embryo devel opment characteristics in Robertsonian and reciprocal translocations: a comparison of results with non-translocation cases. Reprod Biomed Online. 2003; 7(5): 563-571.

20. Palermo G, Joris H, Devroey P, van Steirteghem AC. Pregnancies after intracytoplasmic injection of single spermatozoon into an oocyte. Lancet. 1992; 340(8810): 17-18.

21. Greger V, Knoll JH, Wagstaff J, Woolf E, Lieske P, Glatt H, et al. Angelman syndrome associated with an inversion of chromosome 15q11.2q24.3. Am J Hum Genet. 1997; 60(3): 574-580.

22. Saito-Ohara F, Fukuda Y, Ito M, Agarwala KL, Hayashi M, Matsuo M, et al. The Xq22 inversion breakpoint interrupted a novel Ras-like GTPase gene in a patient with Duchenne muscular dystrophy and profound mental retardation. Am J Hum Genet. 2002; 71(3): 637-645.

23. Anton E, Blanco J, Egozcue J, Vidal F. Sperm studies in heterozygote inversion carriers: A review. Cytogenet Genome Res. 2005; 111(3-4): 297-304.

24. Morel F, Laudier B, Guérif F, Couet ML, Royère $\mathrm{D}$, Roux $\mathrm{C}$, et al. Meiotic segregation analysis in spermatozoa of pericentric inversion carriers using fluorescence in-situ hybridization. Hum Reprod. 2007; 22(1): 136-141.

25. Bhatt SS, Manvelyan M, Moradkhani K, Hunstig F, Mrasek K, Puechberty J, et al. Inverted segment size and the presence of recombination hot spot clusters matter in sperm segregation analysis. Cytogenet Genome Res. 2014; 142(2): 145-149.

26. Batanian J, Hulten MA. Electron microscopic investigations of synaptonemal complexes in an infertile human male carrier of a pericentric inversion inv(1) (p32q42). Regular loop formation but defective synapsis including a possible interchromosomal effect. Hum Genet. 1987; 76(1): 81-89.

27. Fiorentino F, Spizzichino L, Bono S, Biricik A, Kokkali G, Rienzi L, et al. PGD for reciprocal and Robertsonian translocations using array comparative genomic hybridization. Hum Reprod. 2011; 26(7): 1925-1935. 
28. Boklage CE. Survival probability of human conceptions from fertilization to term. Int J Fertil. 1990; 35 (2): 75, 79-80, 81-94.

29. Schmid M, Hofmann R, Köhler J, Jannek U. Familial paracentric inversion: inv(2)(q31q36). Hum Genet. 1985; 71(3): 270-272.
30. Donti E, Rosetti A, Carloni I, Venti Donti G. A new case of familial paracentric inversion of chromosome 2. Hum Genet. 1987; 75(2): 195.

31. Lin CC, Bowen P, Hoo JJ. Familial paracentric inversions inv(2)(q31q35) and inv(8)(q22.3q24.13) ascertained through reproductive abnormalities. Hum Genet. 1987; 75(1): 84-87. 